\title{
Editorial: Innovation in Cements for Sustainability
}

\author{
John L. Provis ${ }^{1 *}$, Miroslav Komljenovic ${ }^{2}$ and Maria C. G. Juenger ${ }^{3}$ \\ ${ }^{1}$ Department of Materials Science and Engineering, University of Sheffield, Sheffield, United Kingdom, ${ }^{2}$ Department of \\ Materials Science, Institute for Multidisciplinary Research, University of Belgrade, Belgrade, Serbia, ${ }^{3}$ Department of Civil, \\ Architectural and Environmental Engineering, University of Texas at Austin, Austin, TX, United States
}

Keywords: cement, sustainability, construction, concrete, alkali-activated (AA) cement

\section{Editorial on the Research Topic}

\section{Innovation in Cements for Sustainability}

Sustainability is trying to balance economic growth, environmental protection and social progress with future technologies, while supporting innovation, and not compromising the way of life for present and future generations. The idea of sustainability should bring people together to foster the biosphere for the benefit of all living beings on our planet Earth.

It is with great pleasure that we present this Research Topic on Innovation in Cements for Sustainability. The collection of 10 articles in this Research Topic represent some very exciting advances in how we design, use, and analyse cementitious materials, and we expect that this work will lead to further advances along the pathway toward sustainability for the construction materials sector.

The work presented here related to Portland cement includes a pioneering study of tricalcium silicate hydration under microgravity conditions (Moraes Neves et al.), and important work on reducing Portland cement production temperatures using increased iron content in the clinker (Elakneswaran et al.). Portland-blended cements are highlighted through work on improving metakaolin dispersion in mortars (Geng et al.), and on the use of nano-alumina to improve the strength and microstructure of high-volume blended cements (Shaikh and Hosan). Hybrid alkaline-belite cements, which involve aspects of both conventional cement and alkali-activation chemistry, are also presented (Sánchez-Herrero et al.).

The development of innovative approaches to the activation of aluminosilicates to produce non-Portland cements is also addressed, using phosphate activators (Wang et al.) and also alkaline waste soda residues (Song et al.) as pathways to produce cements with novel characteristics. The combination of mechanical and chemical activation of fly ash was demonstrated as a way to unlock the potential to produce high-performing binders from ashes of various quality levels (Fernández-Jiménez et al.). The use of new precursors to produce alkali-activated binders has also shown exciting results in materials designed for key applications: heat-resistant porous cementitious materials produced from a combination of wastes from different industries (Bajare et al.), and also innovative mixed-valence ferrosilicate/ferrisilicate binders from synthetic iron-rich slags (Peys et al.).

The Guest Editorial team is confident that this collection of papers will be of benefit to the broader community in research and application of cementitious materials. 


\section{AUTHOR CONTRIBUTIONS}

All authors participated in drafting and approving this Editorial.

Conflict of Interest: The authors declare that the research was conducted in the absence of any commercial or financial relationships that could be construed as a potential conflict of interest.
Copyright (C) 2019 Provis, Komljenovic and Juenger. This is an open-access article distributed under the terms of the Creative Commons Attribution License (CC BY).

The use, distribution or reproduction in other forums is permitted, provided the original author(s) and the copyright owner(s) are credited and that the original publication in this journal is cited, in accordance with accepted academic practice. No use, distribution or reproduction is permitted which does not comply with these terms. 